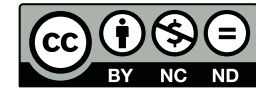

Estudos Teológicos foi licenciado com uma Licença Creative Commons Atribuição - NãoComercial - SemDerivados 3.0 Não Adaptada

http://dx.doi.org/10.22351/et.v57i1.2927

\title{
"Águas vivas" no Evangelho Segundo João, na Bíblia Hebraica e nos manuscritos do Mar Morto: ENTRE CONTINUIDADES E DIFERENÇAS ${ }^{1}$
}

\author{
"Living Waters" in the Gospel of John, in the Hebrew Bible \\ and in the Dead Sea Scrolls: between continuities and differences
}

Cesar Motta Rios ${ }^{2}$

Resumo: O artigo desenvolve um estudo da expressão "água viva" utilizada no Evangelho segundo João, considerando usos de expressão correspondente na Bíblia Hebraica e, em especial, nos manuscritos do mar Morto. Primeiramente, apresenta uma análise de "água viva" em seu sentido literal. Em seguida, propõe um entendimento de seu sentido profundo. Por fim, ocorrências encontradas nos manuscritos do mar Morto são expostas, e o que se verifica nesse conjunto de textos é cotejado com o que se encontra no evangelho joanino. A comparação favorece o entendimento do texto joanino, tanto por haver um paralelo que esclarece o sentido de "água viva" quanto por revelar o que haveria de diverso no conceito e na dinâmica joaninos.

Palavras-chave: Águas vivas. Evangelho de João. Qumran. Bíblia Hebraica. Semântica.

Abstract: This article develops a study of the expression "living waters" used in the Fourth Gospel, taking into account uses of a similar expression in the Hebrew Bible and, especially, in the Dead Sea Scrolls. First, it presents an analysis of the literal meaning of "living waters". Next, it proposes an understanding of the hidden meaning. Finally, pertinent occurrences of "living water" in Dead Sea Scrolls are exposed, and what is verified in this corpus is compared to the understanding proposed for the expression in Johannine Gospel. This comparison foments the understanding of the Johannine text in two ways: because of the existence of a parallel that shed light to the meaning of "living waters", and because it reveals what is diverse in the Johannine concept and dynamic. Keywords: Living Waters. Gospel of John. Qumran. Hebrew Bible. Semantics.

\footnotetext{
1 O artigo foi recebido em 17 de janeiro de 2017 e aprovado em 19 de abril de 2017 com base nas avaliações dos pareceristas ad hoc.

2 Pesquisador independente, integrante do Núcleo de Estudos de Hebraico (EST). Licenciado em Letras: Espanhol (UFMG); bacharel em Letras: Grego (UFMG); mestre em Estudos Clássicos (UFMG); doutor em Literaturas Clássicas e Medievais (UFMG); pós-doutorado em Filosofia Antiga (UFMG). Atualmente, estuda Teologia (ULBRA) com finalidade eclesiástica e integra o Núcleo de Estudos de Hebraico (EST). Contato: cesarmottarios@gmail.com
} 


\section{Introdução}

Figuras de linguagem com duplo sentido, como a metáfora, costumam não ser de fácil interpretação. Por vezes, o debate em torno do entendimento preciso de uma pequena frase pode se estender por séculos. Quando o responsável pela construção não está disponível para ou disposto a elucidar a questão, o sentido correto por ele pretendido pode permanecer na incerteza. Estamos diante de um caso assim. Tudo que temos é o texto.

Neste estudo, exponho a complexidade do problema semântico levantado pela metáfora da "água vivente" no Evangelho segundo João, ensaiando uma interpretação plausível e razoavelmente demonstrada. Ademais, considerando a interpretação que será apresentada, proporei um cotejo com o que se diz sobre "água viva" nos manuscritos do mar Morto. Essa comparação revelará diferenças e continuidades. As continuidades poderão ajudar a fornecer mais suporte para a interpretação proposta. As diferenças revelarão algo que há de característico no movimento de Jesus, o que pode, inclusive, estar em oposição aberta e declarada ao que se encontrará nos textos copiados e guardados pela comunidade de Qumran.

\section{Identificação da imagem}

Metáforas se constroem a partir de imagens que apresentam um sentido mais profundo. Já que esse sentido profundo guarda alguma relação com a imagem, é preciso, inicialmente, identificar bem tal imagem. É erro comum a elucubração de hipóteses a respeito do sentido profundo (figurado) sem a tentativa prévia de uma melhor apreensão do sentido da superfície (figura).

Atualmente, em português, indicamos com o sintagma "água viva" um animal marinho que parece ser água, mas que tem vida. Obviamente, não é essa a imagem evocada por Jesus nos capítulos 4 e 7 do Evangelho segundo João. ${ }^{3}$ Parece, isto sim, que a imagem evocada é quase oposta: algo que é água, mas que parece ter vida. Passo a demonstrar que "água viva", para os primeiros leitores do evangelho e para os interlocutores de Jesus, era obviamente uma água em movimento, água de boa qualidade, de fonte ou curso d'água. Isso requererá um breve passeio por textos mais antigos e aproximadamente contemporâneos.

3 Não há espaço para discutir questões relacionadas com a redação do evangelho, a historicidade dos discursos e diálogos nele contidos e todas as incertezas sobre autoria e hipóteses relacionadas a uma "comunidade joanina". Apenas ressalto que, diferente do que se costumava supor, já não é possível considerar como absoluta no meio acadêmico a tendência de se atribuir a uma característica própria da "comunidade joanina" a gênese de certas passagens do Evangelho segundo João (cf. CIRAFESI, Wally V. The "Johannine Community" in (More) Current Research: A Critical Appraisal of Recent Methods and Models. In: Neotestamentica, v. 48, n. 2, p. 341-364, 2014). De todas as formas, um leitor mais conservador pode ler minhas referências às falas de Jesus como simples e diretamente relacionadas com o personagem histórico. Outro, por sua vez, poderá lê-las como se referindo a esse personagem construído no texto, seja qual for sua perspectiva específica. Uma ou outra opção não acarretará em perda significativa para meu argumento. 
De início, remeto a Jeremias 2.13. O texto contrapõe uma fonte de "águas vivas" (מַים חַיִיִים) a cisternas. A construção ressalta a oposição entre "águas vivas" e águas estanques de pouca qualidade. Há também diversas outras ocorrências do mesmo sintagma na Bíblia Hebraica e na LXX (por exemplo, Gn 26.19 e Ct 4.15) que não sugerem um sentido metafórico para a imagem da água evocada. Simplesmente referem-se à água em movimento ou de boa qualidade. Não é, pois, extraordinário que a mesma expressão מַיִ חַיִים seja frequentemente traduzida por "água corrente" (cf. Lv 14.5 ou Nm 19.17).

Mas como uma água fresca ou em movimento teria relação com a ideia de "vida" para que o adjetivo חַ fosse utilizado para caracterizá-la? Talvez a conexão esteja no fato de que ela possibilita a vida de plantas e outras criaturas. Mas não será o caso de pensarmos que é água boa, fresca, justamente por não ser água estanque? Ou seja, a "vida" da água seria esse movimento. Nesse caso, lembro que, como adiantei, apesar de inanimada, a água corrente ou a jorrar parece comportar-se como ser vivo.

É notável que o uso da expressão com esse sentido se perpetua para além do âmbito da Bíblia Hebraica e para além do idioma semítico. Em um período muito próximo ao da composição do Evangelho segundo João, encontramos a Didaqué, que parece provir de, no máximo, inícios do século II d.C. ${ }^{5}$ Ao orientar sobre o batismo

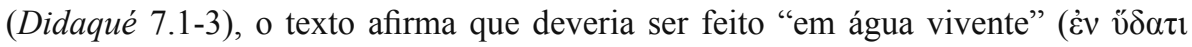
$\zeta \tilde{\omega} \vee \tau \imath)$. Caso não houvesse "água vivente" disponível, dever-se-ia usar qualquer água, fria ou quente. Caso nem isso se tivesse, seria permitido simplesmente verter três vezes água sobre a cabeça do batizando. Essa água vivente não tem nada de simbólico

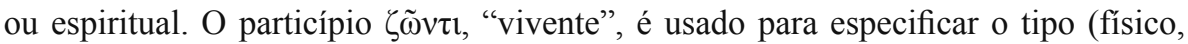
natural) da água. É um tipo de água que não estaria disponível em todas as ocasiões de batismo. Parece sensato entender que se tratasse especificamente de água corrente de rio ou de fonte. Aqui, "água vivente" não pode ser nem mesmo "água fresca ou de boa qualidade" simplesmente, uma vez que o texto certamente não sugeriria, em seguida, verter água suja na cabeça do batizando. Há, pois, uma oposição entre água parada e "água vivente", como em Jeremias 2.13, o que deixa claro que se trata, muitas vezes, de água corrente.

Por haver esse sentido literal acessível aos leitores da Torá no século I d.C., fossem eles judeus ou samaritanos, em João 4.11, aquela mulher samaritana que conversa com Jesus não questiona $o$ que viria a ser tal "água vivente”, mas simplesmente pergunta de onde ( $\pi$ ó $\theta \varepsilon v$ ) Jesus a tiraria. ${ }^{6}$ João Crisóstomo percebeu isso e o expôs de modo claro: “A mulher ouviu 'água viva' antes disto, mas não entendeu. Visto que,

4 A versão grega usa uma construção com genitivo atributivo (v̋ $\delta \alpha \tau \varsigma \zeta \omega \tilde{\eta} \varsigma$ ), diferindo na forma da expressão joanina, que usa um particípio presente, mas a imagem evocada é a mesma.

5 Cf. DRAPER, J. A. Missing Pieces in the Puzzle or Wild Good Chase? A Retrospect and Prospect. In: DRAPER, J. A.; JEFFORD, C. N. (eds.). The Didache: A Missing Piece of the Puzzle in Early Christianity. Atlanta: Scholars Press, 2015. p. 529-544.

6 A samaritana parece mesmo entender que Jesus fala de simples água. Por isso o que se desenrola entre os versículos 10 e 11 pode ser exemplo de um "mal-entendido joanino" (PEIRANO, Ana Maria Casarotti. Jesús y la Samaritana: una lectura de Jn 4,5-26. 2011. 146f. Dissertação (Mestrado) - Programa de Pós-Graduação em Teologia da Faculdades EST, São Leopoldo, 2011. p. 75). 
com efeito, água 'viva' também se chama aquela que jorra continuamente, sempre fluindo, de fontes que não se interrompem, a mulher entendeu que era disso que se estava falando" (PG 59, col. 183). Posteriormente, ela pedirá da água oferecida com o objetivo de nunca mais ter sede (Jo 4.15). Contudo, ela fará isso não por causa da expressão "água vivente", mas por causa da descrição que Jesus mesmo faz dessa água oferecida por ele (Jo 4.13-14). Ou seja, não é a expressão em si, mas a descrição adicional o que faz a samaritana perceber que não se trata de água ordinária. Com algum atraso, a personagem e os primeiros leitores perceberiam que estavam diante de uma metáfora. Essa água não é água. Em sentido mais profundo, essa água é outra coisa.

\section{Associação da imagem (sentido literal) a outro sentido (sentido metafórico)}

O que a imagem de "água corrente" pode indicar metaforicamente? Procuro responder a essa pergunta com dois movimentos. Primeiro, busco na Bíblia Hebraica, arquivo textual muito importante no universo discursivo de Jesus, do evangelho joanino e de seus primeiros leitores, algo que seja associado à imagem da água corrente.

Lembro de versos muitíssimo conhecidos do Salmo 1. Águas correntes, isto é, canais de água, são assemelhados à Torá. A pessoa que medita constantemente na Torá, que tem contato permanente com esse discurso ( $\mathrm{Sl} 1.2$ ), é comparada a uma árvore que tem contato permanente com águas correntes (Sl 1.3). Acrescento, em seguida, um provérbio não tão frequentemente citado:

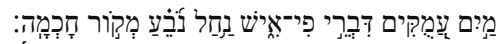

Águas profundas são as palavras da boca de um homem; torrente que jorra é a fonte de sabedoria $(\mathrm{Pv} 18.4)^{7}$

As palavras que saem da boca de uma pessoa são assemelhadas a um rio, a água corrente. Inclusive, deve-se notar que essa relação está tão arraigada no idioma que o verbo que traduzi por “jorrar”, nava', também é usado figurativamente para se referir ao ato de proferir palavras. O fluxo dos discursos está relacionado ao fluxo das palavras. ${ }^{8}$

É certo que a Bíblia Hebraica influenciava a linguagem dos judeus do século I d.C. Por isso é importante essa constatação de que a associação entre discurso e água corrente não é estranha nesse corpus. Ainda assim, não seria metodologicamente cuidadoso ler somente um texto do século I d.C. isoladamente, o Evangelho segundo

Todas as traduções são de responsabilidade do autor.

8 Lembro que esse tipo de associação é culturalmente estabelecido e transmitido pela linguagem. Em outro contexto, o movimento das palavras para fora da boca em direção ao ouvinte pode ser associado a outra imagem, como, por exemplo, aves ou flechas em voo, como é o caso da expressão ह̌ $\pi \varepsilon \alpha \pi \tau \varepsilon \rho o ́ \varepsilon v \tau \alpha$, "palavras aladas", comum na épica homérica (cf. Ilíada 1.201 entre dezenas de outras ocorrências). A relação entre certa imagem da natureza e certa ação humana não é dado natural, mas algo codificado em grupos específicos, e transmitido/herdado por grupos específicos. 
João, e considerar imediatamente que a figura de linguagem ali construída carrega uma característica semelhante à daquelas construções verificadas na Bíblia Hebraica.

É importante, então, reconhecer que algo semelhante se dá na obra de Fílon de Alexandria, contemporâneo de Jesus de Nazaré. ${ }^{9}$ A obra filoniana, como João, insere-se em âmbito judaico ${ }^{10}$ e também está escrita em grego. No decorrer de uma interpretação do sonho do Faraó (Gn 41.17), o alexandrino afirma que "rio" é símbolo dos discursos e fundamenta sua proposta por meio de uma analogia bastante clara:

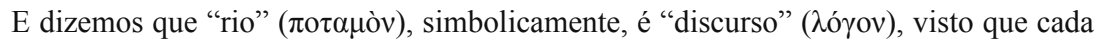
um dos dois é trazido para fora, e, fluindo, tem intensa velocidade. E cada um, algumas vezes, abunda em inundações - um de água, o outro de verbos e nomes. Mas, outras vezes, míngua, enfraquecendo e baixando. E ambos são úteis, certamente, um para os campos arados dos homens, o outro para as almas dos que são afeiçoados a discursos. E também há vezes em que, ao se levantarem em ondas, produzem danos, um ao inundar a terra vizinha, o outro ao misturar e confundir o raciocínio daquele que não se mantém atento. (Sobre os Sonhos 2.238-239)

Temos, então, além do testemunho importante da própria Bíblia Hebraica, uma evidência explícita de período pouco anterior ao do evangelho demonstrando que a associação entre discursos e a imagem de água corrente não seria algo inusitado.

É pertinente entender que, ao falar de águas correntes, Jesus se refere metaforicamente, ou melhor, quase alegoricamente, como direi logo, a palavras que sairiam de bocas humanas. São palavras que haveriam de sair do interior daqueles que recebessem das palavras (da água corrente) do próprio Jesus. Há uma informação importante em João 7.37-39. Após relatar a fala de Jesus, que afirmava que os que creem nele teriam águas vivas saindo de seus interiores, o evangelista informa que ele havia dito aquilo com respeito ao Espírito Santo, que haveria de ser recebido pelos que cressem nele. ${ }^{11}$

9 A obra de Fílon precede a redação do Evangelho segundo João. Há vasta produção acadêmica sobre possíveis influências fílonianas sobre o corpus joanino. Embora não me pareça possível afirmar uma dependência, reconheço como inegável a existência de convergências, que indicam algum compartilhamento de tradições e contexto discursivo, sendo a mais conhecida, mas não a única delas, a semelhança referente à teologia do lógos (cf. BOYARIN, Daniel. The Gospel of the Memra: Jewish Binitarianism and the Prologue to John. In: The Harvard Theological Review, v. 94, n. 3, p. 243-284, Jul. 2001). A potencialidade que a obra fílonniana tem para esclarecer aspectos do evangelho não está esgotada. Ainda há espaço para novas pesquisas. Recentemente, por exemplo, Peder Borgen notou que a obra de Fílon pode ser significativa para a correta apreciação da forma, isto é, do gênero discursivo do quarto evangelho em seu contexto literário mais amplo (BORGEN, Peder. Can Philo's In Flaccum and Legatio ad Gaium be of help? In:__. The Gospel of John: More Light from Philo, Paul and Archaeology - The Scriptures, Tradition, Exposition, Settings, Meaning. Leiden: Brill, 2014. p. 242-260).

${ }^{10}$ Uma leitura superficial poderia sugerir que o âmbito judaico não é compartilhado pelo Evangelho segundo João. Contudo, com Daniel Boyarin, entendo ser precipitado negar a judaicidade do documento (cf. BOYARIN, Daniel. What kind of Jew is an Evangelist? In: AICHELE, G.; WALSH, R. Those Outside: Noncanonical Readings of Canonical Gospels. New York; London: T\&T Clark, 2005. p. 109-153).

11 Uma solução comumente aceita para o texto é o entendimento de que é proposta uma relação direta entre água e Espírito. Há fundamento para tal leitura. Em Isaías 44.3, a oração "verterei água sobre o sedento" aparece em relação de paralelismo com "verterei meu Espírito sobre tua descendência"

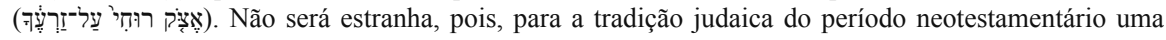


Pois bem, se, como proponho, as águas correntes são palavras que fluiriam de dentro dos cristãos, qual o lugar do Espírito Santo? A água que Jesus ofereceria à mulher samaritana se tornaria uma fonte $\left(\pi \eta \gamma \grave{\eta}-J_{0} 4.14\right)$, que jorraria. Ou seja, temos não só a imagem da água corrente, mas também a de uma fonte. Se a água indica as palavras, o Espírito Santo, mencionado em João 7.37-39, pode ser entendido justamente como essa fonte. A relação entre as imagens e os significados profundos poderia ser a seguinte: águas correntes/que jorram são palavras da Boa-Nova de Cristo; fonte dessas águas é o Espírito Santo; lugar dessa fonte são os que creem.

\section{O significado em ação e sua coerência}

Antes de observar a coerência do sentido proposto, preciso esclarecer que suspeito que o discurso de Jesus possa ser lido não como simples metáfora. Há provavelmente uma alegoria, isto é, não há só elementos com significados metafóricos, mas mais de um elemento com significado profundo; e esses elementos estão relacionados em uma ação. Há uma fonte, há uma água, e há um fluir, que jorra mais da mesma água, que se torna fonte, e o ciclo continua. Tomando os significados que sugeri, coloquemo-los em movimento, para verificar como a narrativa funciona.

O discurso (água corrente) de Jesus (por isso, em um primeiro momento somente, Jesus, ele mesmo, também é a fonte) faz com que o Espírito Santo (a fonte de água corrente) seja recebido no interior daquele que crê. O discurso (água corrente, testemunho, proclamação) desse que crê é concedido pelo Espírito Santo e produz fé em outras pessoas. Essas pessoas que recebem desse discurso (dessa água corrente) também recebem o Espírito Santo. Elas também produzirão discursos com o mesmo efeito (águas correntes), pois também terão o Espírito (fonte de águas correntes).

Resta um movimento de verificação: essa narrativa condiz com aquilo que outros textos conceitualmente aproximados, isto é, especialmente os textos neotestamentários entendem como ação do Espírito Santo nos que creem? Parece-me que sim. A obra do Espírito Santo no Novo Testamento é tida como essencialmente discursiva. Ele ensina (Jo 14.16) e refuta, convence (Jo 16.8), atividades que se realizam pelo discurso. Indo além do Evangelho segundo João, o Espírito Santo, já no momento de sua descida na festa de Pentecostes conforme o relato lucano, se faz perceber por um milagre que envolve o discurso. Os apóstolos falam e cada ouvinte escuta em sua

associação próxima entre a ação do Espírito Santo e a purificação pelo banho ritual, o que se verifica nos MMM (cf. HARRINGTON, Hannah K. Purification in the Fourth Gospel in Light of Qumran. In: COLOE, M. L.; THATCHER, T. (eds.). John, Qumran, and the Dead Sea Scrolls: Sixty Years of Discovery and Debate. Atlanta: SBL, 2011. p. 137). Esse fato, associado ao registrado em João 7.37-39, pode nos levar a uma identificação simbólica entre "água" e "Espírito". Não obstante essa possibilidade, considero viável a exploração de uma relação mais complexa entre esses dois elementos, pelo menos em João 4. Isso não significa que o Espírito não esteja em vista na elaboração semântica, mas que sua identificação com a "água" não precisa ser direta. Embora afirme que as Escrituras chamam o Espírito Santo de "água”, João Crisóstomo dá um pequeno passo a meu favor ao ponderar: "A graça do Espírito, a Escritura uma vez a chama de fogo, outra vez de água, demonstrando que essas palavras são indicativas não da essência

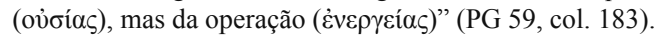


própria língua (At 2.4-8). Em seguida, Pedro se levanta e, justamente, profere um discurso, exortando com várias palavras (At 2.40). Esse discurso é recebido e muitas pessoas creem.

Se o Espírito Santo figura como a fonte e a tal água corrente é o discurso, o Evangelho segundo João prenuncia em linguagem alegórica algo muito próximo ao que se ensina em linguagem direta em Mateus 10.18-20. O Espírito profere discursos, que saem (ou fluem) de dentro dos discípulos. ${ }^{12}$

Neste ponto da reflexão, é preciso fazer ainda outra observação sobre o sentido de "águas vivas". Embora a imagem do sintagma seja a de águas correntes e seu sentido metafórico seja relacionado ao discurso, o significante $\zeta \tilde{\omega} v$, "vivente", é apro-

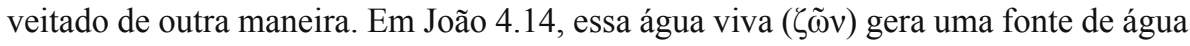

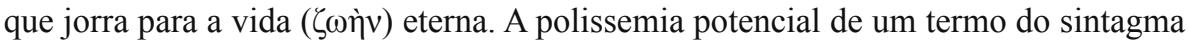
cristalizado com sentido concreto é aproveitada de modo notável. Com isso em mente, lembro de Ezequiel 47 e da visão das águas que saem do Templo e trazem vida (47.9). Não me parece difícil entender que Jesus já propõe a si mesmo como Templo, e, ao mesmo tempo, atribui a seus seguidores semelhante condição (cf. 1Co 6.19). Seria a partir desse tipo de perspectiva, e pensando em Ezequiel, que Jesus se referiria às

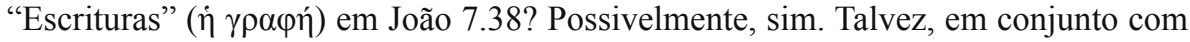
Zacarias 14.8. As águas correntes que fluiriam a partir de Jerusalém no dia prenunciado pelo profeta podem ser hermeneuticamente apropriadas pelo nazareno como indicando o novo discurso que, inicialmente, fluiria a partir da cidade.

Parece-me, até este momento, plausível a interpretação que proponho: a fonte da água é o Espírito e a água é o discurso, o ser humano é o lugar em que está a fonte, de onde flui a água.

\section{"Águas vivas" nos manuscritos do mar Morto ${ }^{13}$}

São muitos os textos dos manuscritos do mar Morto - MMM que contribuem para a compreensão do texto neotestamentário, seja para o fomento de um melhor entendimento do contexto histórico-cultural, seja para o estudo de questões linguís-

12 Também em certos textos dos MMM, o Espírito Santo aparece associado ao conhecimento e ao discurso (TIGCHELAAR, Eibert. Historical Origins of the Early Christian Concept of the Holy Spirit: perspectives from the Dead Sea Scrolls. In: FREY, Jörg; LEVISON, John R. The Holy Spirit, Inspiration, and the Cultures of Antiquity: Multidisciplinary Perspectives. Berlin: de Gruyter, 2014. p. 231-232). Lembro que, como assinalei na nota 11, minha proposta não exclui o Espírito da construção semântica elaborada a partir da imagem da "água corrente". Ele está associado à “água”, mas de forma menos direta, pela mediação do elemento "discurso".

${ }^{13}$ Não se deve tomar os MMM como um corpus homogêneo e produzido por um único grupo (SCHOFIELD, Alison. From Qumran to the Yahad: A New Paradigm of Textual Development for The Community Rule. Brill: Leiden, 2009. p. 55). Por outro lado, o conjunto de manuscritos não parece ser completamente aleatório, pois se trata de uma coleção de textos mormente relacionados ideologicamente entre si (SCHOFIELD, 2009, p. 58). Em meu argumento, procuro reconhecer os MMM como depositários de tradições judaicas antigas, mas não imponho a eles uma coerência que não lhes é inerente. 
ticas ou conceituais a partir de paralelos pontuais. ${ }^{14}$ Para este estudo sobre o tema da "água viva" no texto joanino, os MMM contribuirão de ambas as formas. Por um lado, eles podem servir como testemunho de uso semelhante da expressão. Por outro lado, podem revelar, por contraste, o que há de realmente novo na proposta do quarto evangelho com respeito a um dado do entorno cultural.

Nem todas as ocorrências da expressão "água viva” ou "águas vivas" nos MMM têm a mesma relevância para a presente investigação. A seguir, comento somente as mais importantes. ${ }^{15}$

Em 11Q19 (Col. XLV), manuscrito em hebraico proveniente do período herodiano, mais conhecido pelo título Rolo do Templo, aparece a expressão em uma apropriação do fraseado de Levítico (cf. Lv 15.13; 16.26-28). Com vistas à purificação, ordena-se que a pessoa banhe toda a sua carne, isto é, seu corpo, em "águas vivas" (במים חיים), o que indica obviamente águas boas, correntes.

Essa ocorrência apenas retoma o texto bíblico e reforça a pertinência do sentido literal, o sentido da imagem, que foi demonstrado no primeiro tópico deste estudo. De qualquer forma, trata-se de uma contribuição desse documento a respeito da vitalidade, em período bastante aproximado ao de Jesus, da linguagem antes utilizada na Torá.

As ocorrências que nos restam são especialmente importantes, uma vez que parecem indicar um uso que extrapola o sentido literal. Duas delas estão em um hino preservado no $1 \mathrm{QH}^{\mathrm{a}}$. O hino começa como um cântico de ação de graças por Deus ter me plantado em uma espécie de jardim bem regado, junto a correntes de água, apesar de estar em uma região árida. Na descrição desse jardim, aparecem árvores bem plantadas, que soltam brotos em uma plantação eterna. Para tanto, estendem suas raízes até

${ }^{14}$ BROWN, Raymond E. The Dead Sea Scrolls and the New Testament. In: CHARLESWORTH, James H. (ed.). John and Qumran. London: Geoffrey Chapman, 1972. p. 2-3. Para ressaltar a importância dos MMM no que diz respeito ao entorno cultural, basta lembrar que foi esse conjunto de textos que interrompeu a tendência de se atribuir o Evangelho segundo João a um período mais tardio por supostas influências marcadamente helenísticas em sua linguagem abstrata e simbólica. Diante de tantos novos textos descobertos a pouco mais de $20 \mathrm{~km}$ de Jerusalém, escritos mormente em hebraico e aramaico e em período bem antigo, foi necessário reconhecer que o texto de João não seria estranho para aquele contexto da Judeia (BROWN, 1972, p. 8). Quanto à linguística especificamente, é notável que os MMM contribuíram decididamente para uma mudança na compreensão que se tem a respeito do uso do hebraico na Judeia no período romano (cf. SMELIK, Willem. The Languages of Roman Palestine. In: HEZSER, Catherine (ed.). The Oxford Handbook of Roman Palestine. Oxford: Oxford University Press, 2010. p. 124-125). Ademais, demonstrou-se que os textos dos MMM são úteis para a elucidação de questões linguísticas pontuais pertinentes ao Novo Testamento, como se percebe, por exemplo, em JOOSTEN, Jan; KISTER, Menahem Kister. The New Testament and Rabbinic Hebrew. In: BIERINGER, R. et al. (eds.). The New Testament and Rabbinic Literature. Leiden: Brill, 2010. p. 335-350.

15 Algumas ocorrências não serão consideradas pela dificuldade de interpretação ocasionada pelos danos nos manuscritos. Uma ocorrência em 4Q504 (Frags. 1 e 2, Col. V), manuscrito que também traz texto em hebraico e do período herodiano, aparece em trecho bastante deteriorado. Trata da apostasia de Israel e da misericórdia perene de Deus. Mas não há como ter certeza sobre o uso literal ou metafórico das "águas vivas" (מים חיים) mencionadas pouco antes de uma referência ao culto a deuses estranhos. O mesmo problema relacionado com o estado do texto acontece em 4Q418 (Frag. 103 II). 
o curso d'água e abrem seus ramos "para junto de águas vivas" (למים חיים), e "estarão junto à fonte eterna” (ויהי למקור עולם).

Até aqui, apesar de a linguagem manter continuamente o imaginário da natureza, a forma como começa o cântico, como se o cantor estivesse ele mesmo plantado em tal lugar, deixa claro que se está construindo uma imagem com sentido mais profundo. O Salmo 1 é certamente lembrado pelo leitor. E o uso da expressão "águas vivas" reforça a pertinência de minha referência ao Salmo realizada anteriormente. Além disso, estamos mais próximos do tipo de discurso de Jesus, já que não se trata de um texto literal ou de simples comparação. Contudo, ainda não está explícito que essa água seria algo relacionado com o discurso. Poucos versos depois, contudo, haverá maior clareza. Aparece o tema do segredo. Deus oculta o jardim de quem quereria a ele se opor, aquele que vê, mas não conhece, percebe, mas não crê na fonte da vida (מקור חיים). Já é perceptível alguma proximidade com João 4. Mas ainda se revela algo importantíssimo nos versos que seguem:

Mas tu, meu Deus (אלי), puseste na minha boca como um orvalho, uma chuva para todo(s) [... $]^{17}$ e uma fonte de águas vivas (ומבוע מים חיים). (1QH ${ }^{\mathrm{a}}$ Col. XVI 16)

Está claro que as águas vivas estão relacionadas ao discurso, já que a boca é onde está a sua fonte. Além disso, não é um discurso qualquer, como era no caso do trecho de Fílon de Alexandria antes citado, mas de um discurso colocado por Deus mesmo. ${ }^{18}$ Estamos diante de algo muito próximo do que se encontra no Evangelho segundo João. ${ }^{19}$

${ }^{16}$ Em princípio, seria gramaticalmente possível traduzir a expressão por "se tornarão uma fonte eterna", uma vez que a construção do verbo היה com a preposição ל pode ter esse sentido de "tornar-se em". Contudo, a falta de qualquer desenvolvimento no contexto em prol desse sentido sugere que se trate de algo mais direto. A preposição é usada, sobretudo mais tardiamente, ainda na Bíblia Hebraica inclusive, com um sentido mais espacial estático, praticamente como intercambiável com a preposição ב (GESENIUS, W. H. F. A Hebrew and English Lexicon of the Old Testament. Including the Biblical Chaldee. Translated by Edward Robinson. Boston: Crocker and Brewster, 1844. p. 424). No trecho, há uma referência a Isaías 58.11, mas com inovações importantes na linguagem, especialmente nas expressões em questão.

17 Há uma pequena lacuna ilegível entre "todo(s)" e a continuação, mas não deveria conter nada além da continuação do sintagma iniciado. A reconstrução poderia ser algo como "todos os homens" ou "todos os teus homens".

18 Hannah Harrington, que, em seu estudo, está mais diretamente interessada no tema da purificação, observa, a partir desse mesmo trecho, que "metaforicamente, as palavras de Deus são águas purificadoras para a alma seca” (HARRINGTON, 2011, p. 132).

${ }^{19}$ Charlesworth reconhece nessa semelhança um motivo para se pensar em dependência do Evangelho de João para com os responsáveis pelos MMM. O autor ressalta que, em João e nesses escritos, a expressão "água viva" denota uma salvação escatológica, enquanto, na Bíblia Hebraica e nos escritos rabínicos, há simplesmente o sentido de "água corrente" ou "fresca”. Somente nos MMM e em João, a expressão seria tomada como um termo técnico, que significaria realmente "água viva". (É a forma como Charlesworth se refere ao fenômeno que eu interpreto neste estudo como um aproveitamento da polissemia de um dos termos do sintagma na construção do sentido mais profundo para uma expressão de uso comum com um sentido literal concreto.) (CHARLESWORTH, James H. A Study in Shared Symbolism and Language: The Qumran Community and the Johannine Community. In: . The Bible and the Dead Sea Scrolls. Waco, Texas: Baylor University Press, 2006. v. 3: The Scrolls and Christian Origins, p. 138-139). 
Permanece uma questão: Quem canta esse hino? O sujeito gramatical é singular. Isso pode sugerir (sem atestar) que uma figura especial estaria implicada. Muitos estudiosos entendem que a voz em muitos dos hinos em $1 \mathrm{QH}^{\mathrm{a}}$ seria do Mestre de Justiça ${ }^{20}$, figura presente em outros textos dos MMM e que se entende como dotada de conhecimento especial. Como Jesus se coloca como origem das águas viventes que oferece, também na comunidade que produziu o hino, alguém específico teria a fonte. ${ }^{21}$

Isso parece coerente com a outra ocorrência da expressão "águas vivas" especialmente relevante encontrada nos MMM. Ela figura em CD-B, que traz uma cópia do Documento de Damasco ${ }^{22}$. O trecho que nos interessa conclui uma palavra de julgamento contra aqueles que rejeitam os preceitos de Deus. Trata-se de um adendo, que procura enfatizar a perdição daqueles que, uma vez tendo participado do grupo responsável pelo documento, o abandonam:

Assim, todos os homens que se achegaram à nova aliança (בררי החדשה) na terra de Damasco, mas se voltaram, traíram e se desviaram do poço de águas vivas (בבאר מים מחיים ${ }^{23}$, estes não serão contados na assembleia do povo, nem serão inscritos em suas listas. (CD-B XIX)

Se o sentido metafórico atribuído às “águas vivas” em $1 \mathrm{QH}^{\mathrm{a}}$ está em vista também nesse trecho do Documento de Damasco, o que me parece certo, temos aqui uma relação próxima entre a nova aliança (como entendida por aquela comunidade) e uma fonte específica de ensino, detentora da revelação, isto é, de "seu próprio entendimento da Escritura"24. Afastar-se dessa fonte específica significa apostatar-se, e encontrar-se à deriva, sem parte naquilo que o ensino oferece.

\section{Cotejo e reflexão}

Mesmo sem se ocupar com detalhes, o leitor poderá suspeitar de semelhanças entre o que aí se propõe e um conhecido diálogo no qual Jesus, abandonado por muitos após um discurso duro de se ouvir ( $\sigma \kappa \lambda \eta \rho o ́ \varsigma)$, pergunta a seus discípulos se eles também querem partir. Pedro responde: "Senhor, para junto de quem iremos? Tens pa-

${ }^{20}$ Cf. ELLEDGE, C. D. The Bible and the Dead Sea Scrolls. Atlanta: SBL, 2005. p. 83. Ainda recentemente, estudos pontuais sobre $1 \mathrm{QH}^{\mathrm{a}}$ têm considerado como plausível essa hipótese, como, por exemplo NÚÑEZ, César Carbullanca. ¿Una teologia del martirio en $1 \mathrm{QH}^{\mathrm{a}}$ y $4 \mathrm{Q} 491 \mathrm{c}$ ? Aportes para la comprensión de la cristología del Hijo del hombre joánico. In: Veritas, n. 25, p. 119-131, septiembre 2011.

${ }^{21}$ Embora a individualidade da identidade do dono da voz nesse hino favoreça a hipótese que construo, não dependo inteiramente dela. Ainda que não seja o Mestre de Justiça, um indivíduo histórico específico e único, a cantar para a comunidade, é certo que o texto aponta para uma "fonte" histórica específica, geográfica e ideologicamente relacionada com o grupo sectário que faz uso litúrgico do canto.

22 O documento já era conhecido desde antes da descoberta dos MMM, uma vez que havia sido encontrado também na Geniza do Cairo. Sua presença nos MMM, contudo, não é sem importância. Além de contribuir com mais um testemunho do texto, atesta a importância e a antiguidade do documento.

${ }^{23}$ A imagem evocada lembra Jeremias 2.13 e 7.13. O vocabulário utilizado na construção, contudo, não é substancialmente aproximado.

24 HARRINGTON, 2011, p. 133. 
lavras de vida eterna, e nós confiamos e reconhecemos que tu és o santo de Deus!'25 (Jo 6.68). O apóstolo reconhece Jesus como fonte do ensino que outorga a vida eterna, e o status especialíssimo desse mestre. Ao declarar isso, ele não somente afirma algo a respeito de Jesus, mas também nega esse valor a outras propostas. Ele rejeita, portanto, consciente ou não, a delimitação do Documento de Damasco, reconhecendo em Jesus, e não em outro qualquer, a fonte das águas vivas.

Há algo mais a ser dito nessa comparação. Embora Jesus seja reconhecido por Pedro como a fonte por excelência, e ele mesmo se apresente assim à samaritana, acrescenta-se uma novidade que o diferencia radicalmente do que se percebe nos textos transmitidos nos MMM. A “água viva”, isto é, a "água corrente”, que é o ensino que sai de sua boca, quando recebida pelo ouvinte, pode produzir também nele uma fonte. Ou seja, aquele ou aquela que era simplesmente um receptor do ensino, passa a ser também emissor. A fonte original é única, mas a centralidade geográfica, espacial ou mesmo cultural se vê perturbada pelo fato de que essa fonte não produz mera água, mas água que se torna novas fontes. E fica marcada a radicalidade dessa descentralização pelo fato de que uma mulher samaritana ${ }^{26}$ poderia ter a fonte dentro de si, confor-

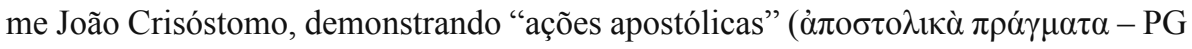
59, col. 184). A salvação viria originalmente dos judeus, mas não fluiria somente dos judeus. ${ }^{27}$ As fronteiras se romperiam.

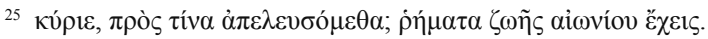

${ }^{26} \mathrm{O}$ leitor deve se lembrar da muito conhecida querela dos judeus contra os samaritanos. Preciso, contudo, fazer uma breve observação a respeito. De fato, judeus não toleravam os samaritanos e não os entendiam como povo de Deus, embora também não os colocassem fácil e simplesmente como gentios. Havia certa ambivalência incômoda, refletida tanto na Mishnah quanto em Josefo (cf. FELDMAN, Louis H. Josephu's Attitude Toward the Samaritans: A Study in Ambivalence. In: MOR, Menachem (Ed.). Jewish Sects, Religious Movements, and Political Parties. Omaha, Nebraska: Creighton University Press, 1992. p. 23-45). Os samaritanos, por outro lado, se entendiam como o verdadeiro povo de Deus, afirmando-se como o autêntico Israel, e excluindo os judeus dessa noção (cf. SCHORCH, Stefan. The Construction of Samari(t)an Identity from the Inside and from the Outside. In: ALBERTZ, Rainer; WÖHRLE, Jakob (ed.). Between Cooperation and Hostility: Multiple Identities in Ancient Judaism and the Interaction with Foreign Powers. Göttingen: Vandenhoeck \& Ruprecht, 2013.p. 135-149). O que os judeus liam em 1 Reis 17 sobre a origem dos samaritanos era ignorado por esses últimos. Só consideravam (e só consideram ainda hoje) a Torá (com algumas pequenas diferenças, sobretudo no que diz respeito ao lugar do Templo) como texto sagrado (cf. BLANC, Luis Fernando Girón. La versión samaritana del Pentateuco. In: 'Ilu. Revista de Ciencias de las Religiones, Anejo VII, 2002. p. 75-82). Agora, é importante o fato de que não se pode dizer simplesmente que os judeus oprimiam os samaritanos. Os samaritanos formavam um grupo étnico enorme. Havia, inclusive, uma diáspora samaritana, com sinagogas em diversas cidades. E esse grande grupo populacional também se mostrava arredio contra os judeus. De certa forma, pode-se dizer que os oprimidos também oprimiam. Um exemplo disso está na ocorrência de assassinatos de judeus galileus que cruzavam a Samaria rumo a Jerusalém (cf. A.J. 20,118). Esse fato não deve diminuir a tensão e o caráter inusitado do diálogo entre Jesus e a samaritana, nem o caráter inovador do que Jesus anuncia pela metáfora das águas vivas. Pelo contrário, podemos perceber Jesus não só anulando uma opressão feita pelo seu lado, mas superando todo um conflito que também tem incidências contra seu lado.

27 Inclusive porque os judeus seguidores de Jesus são, por si mesmos, tão inábeis quanto a samaritana. Eles vão e voltam da cidade, como ela também, mas não proclamam o nome de seu mestre, como ela faz; eles não se arriscam a interpelar Jesus, enquanto ela sim (Jo 4.27); eles, assim como ela, têm dificuldades para entender a linguagem de Jesus além do sentido literal (Jo 4.31-34) (cf. CUVILLIER, Élian. La figure des disciples en Jean 4. In: New Testament Studies, v. 42, p. 252-253, 1996). Essa constatação deveria fazer 
Não há, portanto, centralização definitiva. É algo nesse sentido que o Novo Testamento sugere acontecer após narrar morte, ressurreição e assunção de Jesus. Conforme o relato de Atos, surge uma profusão de novas fontes sendo geradas a partir das fontes deixadas por Jesus em seus discípulos. O ensino produz "ensinadores".

Essa diferença justificaria a descentralização do movimento levado adiante pelos discípulos de Jesus, o qual se deu a conhecer como o caminho ( $\dot{\eta}$ ódò $\zeta$ ), e sua expansão, em contraste com o caráter centralizador, estrito e sectário da comunidade de Qumran e de outros grupos semelhantes. ${ }^{28}$

Outra semelhança notável reside no fato de que, tanto no evangelho quanto nos MMM, o símbolo da água está presente não somente como discurso ou ensino, mas também, e quantitativamente mais inclusive, como elemento de purificação. Seria, pois, recomendável que se pensasse a respeito da relação entre as "águas correntes" discursivas e as águas dos banhos rituais. Não há espaço aqui para refletir sobre isso de forma minuciosa. Apenas sugiro a possibilidade de que encontremos alguma relação na resposta de Jesus à questão do culto correto levantada pela samaritana. A pergunta sobre o culto em Geresim ou Jerusalém é ensejo para que o nazareno fale sobre algo mais profundo: o culto em espírito e em verdade a um Deus que é espírito (Jo 4.23-24). Ora, é possível que o discurso esteja para a água da purificação ritual como o culto espiritual e mais profundamente verdadeiro está para o culto ritual. ${ }^{29}$ Uma coisa, portanto, não eliminaria a outra, mas seria sua realidade mais radical.

\section{Considerações finais}

Este estudo propôs, com argumentos fundamentados em fontes textuais antigas, um entendimento da metáfora (ou alegoria) das "águas correntes/vivas" construída por Jesus no Evangelho segundo João. A aproximação da expressão a outras asse-

o leitor, judeu ou não, desconfiar de sua capacidade e, assim, esperar mais confiadamente na dinâmica do Espírito e da "água vivente" apresentada por Jesus no trecho.

${ }_{28}$ Não obstante, essa diferença que pode parecer favorável ao cristianismo não deveria iludir os adeptos da igreja subsequente. Pelo contrário, com alguma sinceridade na reflexão, é possível que se reconheça que nem sempre (ou, talvez, quase nunca) a igreja soube lidar com essa dinâmica. O ímpeto de centralização, controle e estruturação bem definida não consegue se harmonizar facilmente com o que Jesus oferece aos seus discípulos. De alguma forma, as instituições cristãs estariam mais confortáveis com um Mestre de Justiça do que com um Messias que vai para a cruz, e, cumprindo uma profecia, faz derramar seu Espírito sobre toda carne (J1 2.28; At 2.17).

${ }^{29}$ Harrington percebe tanto no evangelho quanto nos MMM uma relação entre a purificação e a revelação de conhecimento. Os sectários de Qumran valorizariam o banho ritual antes do estudo da Torá. Quanto ao evangelho joanino, a autora menciona passagens que deliberadamente associam a purificação com o discurso em si (Jo 15.3; 17.17). Ela conclui: “Os sectários de Qumran e o autor do Quarto Evangelho discordariam a respeito do papel de Jesus, mas eles certamente compartilhariam uma base comum na performance da purificação ritual para a recepção da revelação divina" (HARRINGTON, 2011, p. 134). Ainda que perspicaz nas referências, parece-me que a conclusão desconsidera um detalhe significativo: os versículos mencionados não associam diretamente a purificação com água a uma preparação para uma revelação posterior, mas falam de uma revelação que purifica. Há aspectos ainda a serem pensados, e talvez não somente do lado joanino da comparação. 
melhadas na Bíblia Hebraica e o recurso a textos gregos cronologicamente próximos do texto joanino demonstraram que, com “águas vivas”, indica-se, no sentido literal, a imagem de água corrente, que, no sentido mais profundo, representa um discurso ou ensinamento oferecido por palavras.

Além disso, a reflexão deixou clara a pertinência de se comparar o discurso do evangelho com textos dos MMM, documentos que revelam dados de um universo discursivo bem próximo daquele da enunciação dos discursos de Jesus e da redação do texto neotestamentário. Essa comparação esclareceu e corroborou, por proximidade, o sentido proposto para a expressão "águas vivas" utilizada por Jesus. Por outro lado, por contraste, lançou luz sobre certo aspecto da rica dinâmica das "águas vivas" na proposta de Jesus. Trata-se da descentralização da função do testemunho e do fazer discípulos, algo perceptível nos primórdios do Caminho conforme o relato de Atos.

\section{Referências}

BIBLIA Hebraica Stuttgartensia. Ediderunt K. Elliger et W. Rudolph. Editio quinta emendata opera A. Schenker. Stuttgart: Deutsche Bibelgesellschaft, 1997.

BLANC, Luis Fernando Girón. La versión samaritana del Pentateuco. In: 'Ilu. Revista de Ciencias de las Religiones, Anejo VII, 2002. p. 75-82. Disponível em: $<$ https://revistas.ucm.es/index.php/ ILUR/article/view/ILUR0202230075A>. Acesso em: 27 jun. 2016.

BORGEN, Peder. Can Philo's In Flaccum and Legatio ad Gaium be of help? In: The Gospel of John: More Light from Philo, Paul and Archaeology - The Scriptures, Tradition, Exposition, Settings, Meaning. Leiden: Brill, 2014. p. 242-260.

BOYARIN, Daniel. What kind of Jew is an Evangelist? In: AICHELE, G.; WALSH, R. Those Outside: Noncanonical Readings of Canonical Gospels. New York; London: T\&T Clark, 2005. p. 109-153.

BOYARIN, Daniel. The Gospel of the Memra: Jewish Binitarianism and the Prologue to John. In: The Harvard Theological Review, v. 94, n. 3, p. 243-284, Jul. 2001.

BROWN, Raymond E. The Dead Sea Scrolls and the New Testament. In: CHARLESWORTH, James H. (ed.). John and Qumran. London: Geoffrey Chapman, 1972. p. 1-8.

CHARLESWORTH, James H. A Study in Shared Symbolism and Language: The Qumran Community and the Johannine Community. In: The Bible and the Dead Sea Scrolls. Waco, Texas: Baylor University Press, 2006. v. 3: The Scrolls and Christian Origins, p. 97-152. CIRAFESI, Wally V. The "Johannine Community" in (More) Current Research: A Critical Appraisal of Recent Methods and Models. In: Neotestamentica, v. 48, n. 2, p. 341-364, 2014. CUVILlIER, Élian. La figure des disciples en Jean 4. In: New Testament Studies, v. 42, p. 245-259, 1996.

DIDACHE. In: Apostolic Fathers. Edited and Translated by Bart D. Ehram. Cambridge, MA: Harvard University Press, 2003.

DRAPER, J. A. Missing Pieces in the Puzzle or Wild Good Chase? A Retrospect and Prospect. In: DRAPER, J. A.; JEFFORD, C. N. (eds.). The Didache: A Missing Piece of the Puzzle in Early Christianity. Atlanta: Scholars Press, 2015. p. 529-544.

ELLEDGE, C. D. The Bible and the Dead Sea Scrolls. Atlanta: SBL, 2005.

FELDMAN, Louis H. Josephu's Attitude Toward the Samaritans: A Study in Ambivalence. In: MOR, Menachem (Ed.). Jewish Sects, Religious Movements, and Political Parties. Omaha, Nebraska: Creighton University Press, 1992. p. 23-45. 
GESENIUS, W. H. F. A Hebrew and English Lexicon of the Old Testament. Including the Biblical Chaldee. Translated by Edward Robinson. Boston: Crocker and Brewster, 1844.

HARRINGTON, Hannah K. Purification in the Fourth Gospel in Light of Qumran. In: COLOE, M. L.; THATCHER, T. (eds.). John, Qumran, and the Dead Sea Scrolls: Sixty Years of Discovery and Debate. Atlanta: SBL, 2011. p. 117-138.

HOMER. The Iliad: Greek text with an English translation by A. T. Murray. Cambridge, MA: Harvard University Press, 1924. v. 1.

JOÃO CRISÓSTOMO. Homiliae LXXXVIII in Joannem. In: MIGNE, J.-P. (Ed.). S. P. N. Joannis Chrysostomi, Archiepiscopi Constinopolitani, Opera Omnia Quae Existant [...] Paris: Migne, 1862. (Patrologia Graeca, 59).

JOOSTEN, Jan; KISTER, Menahem Kister. The New Testament and Rabbinic Hebrew. In: BIERINGER, R. et al. (eds.). The New Testament and Rabbinic Literature. Leiden: Brill, 2010. p. 335-350.

MARCUS, Joel. Rivers of living water from Jesus' belly. In: JBL, v. 117, p. 328-330, 1998.

MARTÍNEZ, Florentino García; TIGCHELAAR, Eibert J. C. (eds.). The Dead Sea Scrolls Study Edition. Leiden; New York; Köln: Brill, 1999. 2 v.

NÚÑEZ, César Carbullanca. ¿Una teologia del martirio en $1 \mathrm{QH}^{\mathrm{a}}$ y $4 \mathrm{Q} 491 \mathrm{c}$ ? Aportes para la comprensión de la cristología del Hijo del hombre joánico. In: Veritas, n. 25, p. 119-131, septiembre, 2011.

PEIRANO, Ana Maria Casarotti. Jesús y la Samaritana: una lectura de Jn 4,5-26. 2011. $146 f$. Dissertação (Mestrado) - Programa de Pós-Graduação em Teologia da Faculdades EST, São Leopoldo, 2011.

PHILO OF ALEXANDRIA. Philo in ten volumes (and Two Supplementary Volumes). COLSON, F. H.; WHITAKER, G. H. (trads.). London: Heinemann; Cambridge, MA: Harvard University Press, 1929-1962.

SCHOFIELD, Alison. From Qumran to the Yahad: A New Paradigm of Textual Development for The Community Rule. Brill: Leiden, 2009.

$\mathrm{SCHORCH}$, Stefan. The Construction of Samari(t)an Identity from the Inside and from the Outside. In: ALBERTZ, Rainer; WÖHRLE, Jakob (ed.). Between Cooperation and Hostility: Multiple Identities in Ancient Judaism and the Interaction with Foreign Powers. Göttingen: Vandenhoeck \& Ruprecht, 2013. p. 135-149.

SMELIK, Willem. The Languages of Roman Palestine. In: HEZSER, Catherine (ed.). The Oxford Handbook of Roman Palestine. Oxford: Oxford University Press, 2010. p. 122-141.

TIGCHELAAR, Eibert. Historical Origins of the Early Christian Concept of the Holy Spirit: perspectives from the Dead Sea Scrolls. In: FREY, Jörg; LEVISON, John R. The Holy Spirit, Inspiration, and the Cultures of Antiquity: Multidisciplinary Perspectives. Berlin: de Gruyter, 2014. p. 167-240.

THE GREEK NEW TESTAMENT. Fourth Revised Edition. Edited by Barbara Aland et al. Stuttgart: Deutsche Bibelgesellschaft, 2000. 